\title{
Case Report: Improvement of Long Lasting Hyperpigmentation by Aqueous Human Placenta Extract (Reju Growth Factor, RGF $^{\circledR}$ ) Treatment
}

\author{
Ruchee Phonchai ${ }^{1,2}$, Bunchob Ubonsaen ${ }^{3}$, Supaluk Brameld ${ }^{4}$, Pimjai Naigovit ${ }^{2}$ \\ ${ }^{1}$ Neuroscience Research Center, Institute of Molecular Biosciences, Mahidol University, Nakhon Pathom, Thailand \\ ${ }^{2}$ LBM Stem Cell Research Unit, Life Balance Methodology Co, Ltd., Bangkok, Thailand \\ ${ }^{3}$ Sangkhom Hospital, Nongkhai Provincial Health Office, Nongkhai, Thailand \\ ${ }^{4}$ National Institute of Health, Ministry of Public Health, Bangkok, Thailand \\ Email: ruchee.pc@gmail.com
}

How to cite this paper: Phonchai, R., Ubonsaen, B., Brameld, S. and Naigovit, P. (2019) Case Report: Improvement of Long Lasting Hyperpigmentation by Aqueous Human Placenta Extract (Reju Growth Factor, RGF ${ }^{\circ}$ ) Treatment. Journal of Cosmetics, Dermatological Sciences and Applications, 9, 125-128.

https://doi.org/10.4236/jcdsa.2019.92011

Received: March 8, 2019

Accepted: May 28, 2019

Published: May 31, 2019

Copyright $\odot 2019$ by author(s) and Scientific Research Publishing Inc. This work is licensed under the Creative Commons Attribution International License (CC BY 4.0).

http://creativecommons.org/licenses/by/4.0/

\section{(c) (i) Open Access}

\begin{abstract}
Hyperpigmentation is a common skin problem in a woman. Prolonging topical use of skin whitening may cause hyperpigmentation such as ochronosis whose condition is a challenge for treatment. An aqueous human placenta extract $\left(\mathrm{RGF}^{\oplus}\right)$ contains bioactive therapeutic molecules. There is evidence of human placenta extract showing that melanin synthesis is inhibited by placenta extract in melanocytes. We first reported the case of the hyperpigmentation improvement following face skin mesotherapy human placenta extract treatment.
\end{abstract}

\section{Keywords}

Hyperpigmentation, Human Placenta Extract, Mesotherapy

\section{Introduction}

Hyperpigmentation is a common skin problem. It presents dark brown patches, usually on the face which is more in women [1]. A common cause of hyperpigmentation is an excessive production of melanin [2] [3]. It is predominantly attributed to hormonal change, ultraviolet exposure and prolonging use drugs or hydroquinone whitening influence [1]. Exogenous ochronosis is caused by prolonged exposure to topical hydroquinone. The side effect as con-sequence use of hydroquinone is challenging to treat [4] [5]. Aqueous human placenta extract is natural medicine which contains bioactive therapeutic molecules such as peptides, polypeptide, and DNA fragment, polydeoxyribonucleotides, proteins, vi- 
tamins, growth factors and hormones [6] [7] [8]. It plays an important role in prevention, alleviation, and cure of the diseases [9]. The aqueous extract human placenta is scientifically proven potent wound healer and skin problem [7] [10] [11]. The evidence of the effect of placenta extract on depigmentation in the clinic is limited. Thus, we present the case of the volunteer who showed the dramatic improvement of hyperpigmentation three months after mesotherapy human placenta extract $\left(\mathrm{RGF}^{\oplus}\right)$ treatment.

\section{Case Report}

A 39-year-old female present with dark brownish hyperpigmentation distributed over face for 4 years. She had prolonged topical used of skin whitening cream containing hydroquinone and corticosteroid for more than 20 years. She volunteered and gave her written informed consent for this study. On physical examination, there were multiple dark brown pigment patches on the face, the cheeks, and bridge of the nose, forehead, chin, and upper lip (Figure 1). A diagnosis is ochronosis due to prolonged use of topical hydroquinone. The volunteer was healthy and routine laboratory investigations were normal. Management of this case is mesotherapy human placenta extract treatment with $\mathrm{RGF}^{\oplus}$ 200 pg/ml, 5 ml (Life Balance Methodology Co., Ltd., Bangkok, Thailand) facial skin intradermal injection once a month for 3 months (Figure 1). There was not any cosmetics or drugs facial skin management during the mesotherapy $\mathrm{RGF}^{\circ}$ treatment. After 3 months of 3 doses of $\mathrm{RGF}^{\circledast}$ treatment, facial hyperpigmentation improved significantly and skin lightened and brightened (Figure 2). Skin firmness was measured with a Cutometer at the end of treatment. On month 3 , the skin increases the relative elasticity recovery of skin (r7) when compared to before treatment (data not shown). The skin elasticity showed improvement after treatment to $60 \%$. The skin was dramatically hydrated and finer skin structure within 3 months after treatment with $\mathrm{RGF}^{\oplus}$. The wrinkle under the eyes was significantly reduced in the first month after treatment.

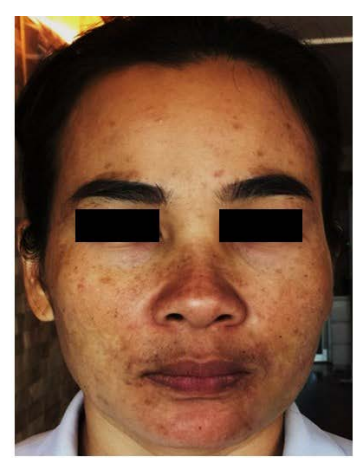

RGF $^{\circledR}$ ID Dose 1

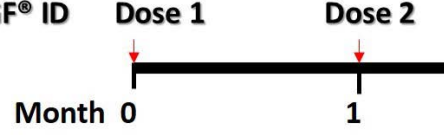

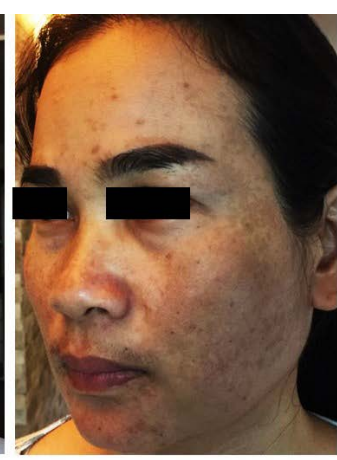

Dose 3 Image capture

Figure 1. Before start $\mathrm{RGF}^{\oplus}$ treatment for 3 doses once months for 3 months; localize dark brown color patch on the cheeks, bridge of nose, forehead, chin, and upper lip. 


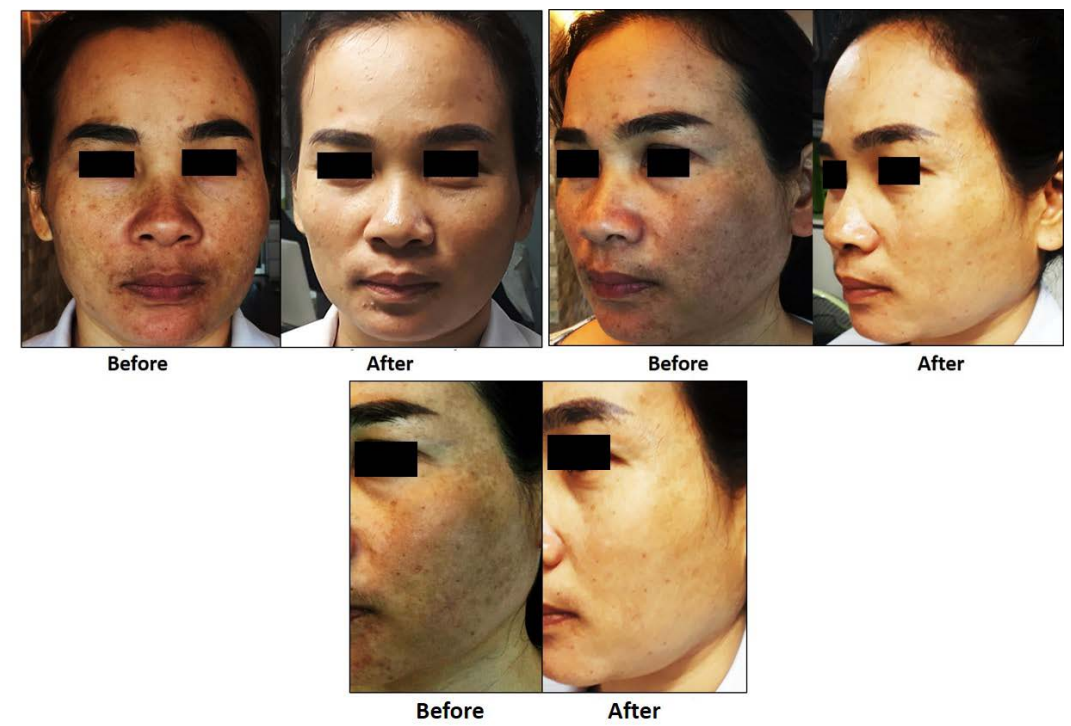

Figure 2. After 3 months of mesotherapy $\mathrm{RGF}^{\circledast}$ treatment, facial hyperpigment was disappeared and the facial skin was lightened and brightened.

\section{Discussion}

Hydroquinone-inducing hyperpigment for melasma is a challenge to treat. The mesotherapy human placental extract treatment has proven to be effective in the improvement of hyperpigmentation and skin complex and elasticity. As we know human placenta extract has been used for treating various skin problem and rejuvenation [11] [12]. It consists of bioactive therapeutic molecule exerting the antioxidative effects [7]. The placenta extract is scientifically proven skin-whitening effect [7] [11] [13] and reduces oxidative stress. It also induces fibroblast proliferation and collagen synthesis [10]. It could inhibit melanin synthesis and also regulate antioxidant genes and might protect the skin against oxidative stress [14] [15] [16]. The skin-whitening effect and the physiological and genetic mechanism had been studied in B16 melanoma cells [2]. The placenta extract could regulate the antioxidant enzyme genes such as cytosolic superoxide dismutase and catalase and inhibit the melanin synthesis by reducing the activity tyrosinase, the melanin synthesis enzyme. In addition, placenta extract protected the $\mathrm{B} 16$ cells from $\mathrm{H}_{2} \mathrm{O}_{2}$-induced cell death [2]. In summary, the mesotherapy of human placenta extract was safe and effective in the improvement of hyperpigmentation. In addition, it also improves skin complexion and elasticity.

\section{Conflicts of Interest}

The authors declare no conflicts of interest regarding the publication of this paper.

\section{References}

[1] Nouveau, S. (2016) Skin Hyperpigmentation in Indian Population: Insights and Best Practice. Indian Journal of Dermatology, 61, 487-495.

https://doi.org/10.4103/0019-5154.190103 
[2] Sarkar, R., Arora, P., Garg, V.J., Sonthalia, S. and Gokhale, N. (2014) Melasma Update. Indian Dermatology Online Journal, 5, 426-435. https://doi.org/10.4103/2229-5178.142484

[3] Vashi, N.A. and Kundu, R.V. (2013) Facial Hyperpigmentation: Causes and Treatment. British Journal of Dermatology, 169, 41-56. https://doi.org/10.1111/bjd.12536

[4] Al-Saleh, I., Shinwari, N., Mashhour, A., Mohamed, G.E.D. and Rabah, A. (2011) Heavy Metals (Lead, Cadmium and Mercury) in Maternal, Cord Blood and Placenta of Healthy Women. International Journal of Hygiene Environment Health, 214, 79-101. https://doi.org/10.1016/j.ijheh.2010.10.001

[5] Gandhi, V., Verma, P. and Naik, G. (2012) Exogenous Ochronosis after Prolonged Use of Topical Hydroquinone (2\%) in a 50-Year-Old Indian Female. Indian Journal of Dermatology, 57, 394-395. https://doi.org/10.4103/0019-5154.100498

[6] Chakraborty, P.D., De, D., Bandyopadhyay, S. and Bhattacharyya, D. (2009) Human Aqueous Placental Extract as a Wound Healer. Journal of Wound Care, 18, 462, 464-467. https://doi.org/10.12968/jowc.2009.18.11.44987

[7] Chakraborty, P.D. and Bhattacharyya, D. (2012) Aqueous Extract of Human Placenta as a Therapeutic Agent. InTechOpen, Rijeka, 77-92.

[8] Chakraborty, P.D., Goswami, S., Bera, S. and Mukhopadhyay, I. (2014) Quantitation of Polydeoxyribonucletides (PDRNs) in Human Placental Extract by Fluorescence Spectroscopy Using Ethidium Bromide. American Journal of Analytical Chemistry, 5, 784-795. https://doi.org/10.4236/ajac.2014.512087

[9] Gupta, R. and Chattopadhyay, D. (2009) Glutamate Is the Chemotaxis-Inducing Factor in Placental Extracts. Amino Acids, 37, 271-277. https://doi.org/10.1007/s00726-008-0143-5

[10] Yoshikawa, C., Takano, F., Ishigaki, Y., Okada, M. and Kyo, S. (2013) Effect of Porcine Placental Extract on Collagen Production in Human Skin Fibroblasts. Gynecology Obstetrics, 3, 1-4. https://doi.org/10.4172/2161-0932.1000186

[11] Pan, Y.P., Mike, K.S., Wong, M.B.F., Klokol, D. and Chernykh, V. (2017) Placental Therapy: An Insight to Their Biological and Therapeutic Properties. Journal of Medical Therapy, 1, 1-6. https://doi.org/10.15761/JMT.1000118

[12] Hong, J.W., Lee, W.J., Hahn, S.B., Kim, B.J. and Lew, D.H. (2010) The Effect of Human Placenta Extract in a Wound Healing Model. Annual Plastic Surgery, 65, 96-100. https://doi.org/10.1097/SAP.0b013e3181b0bb67

[13] Pal, P., Mallick, S., Mandal, S.K., Das, M., Dutta, A.K., Datta, P.K., Bhadra, R., et al. (2002) A Human Placental Extract: In Vivo and in Vitro Assessments of Its Melanocyte Growth and Pigment-Inducing Activities. International Journal of Dermatology, 41, 760-767. https://doi.org/10.1046/j.1365-4362.2002.01524.x

[14] Togashi, S., Takahashi, N., Iwama, M., Watanabe, S., Tamagawa, K. and Fukui, T. (2002) Antioxidative Collagen-Derived Peptides in Human-Placenta Extract. Placenta, 23, 497-502. https://doi.org/10.1053/plac.2002.0833

[15] Rozanova, S., Cherkashina, Y., Repina, S., Rozanova, K. and Nardid, O. (2012) Protective Effect of Placenta Extracts against Nitrite-Induced Oxidative Stress in $\mathrm{Hu}$ manerythrocytes. Cell Molecular Biology Letter, 17, 240-248. https://doi.org/10.2478/s11658-012-0007-6

[16] Yamasaki, M., Hasegawa, S., Takahashi, H., Kobayashi, Y., Sakai, C., Ashizawa, Y., Asai, Y., Kanzaki, M. and Fukui, T. (2015) Placental Extracts Induce the Expression of Antioxidant Enzyme Genes and Suppress Melanogenesis in B16 Melanoma Cells. Natural Product Research, 29, 2103-2106. https://doi.org/10.1080/14786419.2014.986660 